\title{
Reproductive Immunology
}

National Cancer Institute

\section{Source}

National Cancer Institute. Reproductive Immunology. NCI Thesaurus. Code C19318.

The science concerned with the various phenomena of immunity and induced sensitivity associated with the mother and fetus in gesticulating organisms. 